\title{
Towards a New Understanding of Unmet Medical Need
}

\author{
Kyann Zhang ${ }^{1}\left[\right.$ Gayathri Kumar $^{1} \cdot$ Chris Skedgel $^{1} \oplus$
}

Accepted: 17 April 2021 / Published online: 18 June 2021

(c) The Author(s) 2021

\section{Introduction}

'Unmet medical need' (UMN) is a central concept in the incentivisation and development of new health technologies, and the identification of a particular medical need as 'unmet' is intended to encourage innovation in that area [1]. A meaningful distinction is essential for informed decision making and priority setting by a range of stakeholders including public research funders (e.g. Horizon Europe), health regulators (e.g. the European Medicines Agency), national and multi-national health technology assessment (HTA) agencies (e.g. EUnetHTA), patients and patient advocates, and the pharmaceutical industry. Incentives available to these stakeholders include, amongst others, preferential access to public research funds; protocol assistance for small-sized and medium-sized enterprises; access to alternative or 'adaptive' regulatory pathways; consideration of UMN as a value element in HTAs; and financial incentives or innovative payment models at the reimbursement stage. Targeted incentives for innovation around UMN are part of larger efforts to ensure the efficiency, effectiveness, quality, sustainability, safety and affordability of health systems [2], and there was broad agreement at a recent workshop on a pharmaceutical strategy for Europe that incentives are an important tool in ensuring the development of innovative medicines to address pressing health needs [3].

However, despite the centrality of UMN in the development pathway, this concept is not understood in the same way by different stakeholders [4]. Inconsistencies in its understanding diminish the usefulness of UMN as a concept that, at its essence, is meant to distinguish more urgent societal health needs from less urgent needs $[2,4]$. We suggest that, to agree on shared and consistent criteria for distinguishing pressing from less urgent health needs, it will

first be necessary for stakeholders to agree on what they are trying to achieve though this distinction.

\section{Need for Consistency in the Understanding of UMN}

Given the diversity of stakeholders [5] and the range of potential incentives along the drug development pathway, from drug discovery to commercialisation and reimbursement, a shared understanding of what constitutes an UMN is critical to providing a consistent and reliable signal to innovators [4]. Such signals are particularly important where conventional market mechanisms may not otherwise be sufficient to encourage research and commercialisation. However, the same workshop on a pharmaceutical strategy for Europe noted earlier highlighted an increasing perception that there is "no general agreement on a common definition of "unmet medical need" [3]. Similar sentiments were expressed in the 2020 European Union Pharmaceutical Strategy Roadmap, which noted that "innovation efforts are not always aligned with public health and health system needs due to the lack of a common understanding of the concept of UMN amongst stakeholders and decision-makers" [6]. These perceptions are supported by a 2019 review by Vreman et al [4] which found 16 different operational definitions of UMN, many of which differed in substantive respects and were heavily context dependent. The authors grouped these elements into broad categories of concerns over alternative treatments, disease burden and patient population. This lack of alignment means that innovators may not be sufficiently incentivised to invest in the complex science required to address the most urgent health needs in a timely and efficient manner.

Chris Skedgel

cskedgel@ohe.org

1 Office of Health Economics, Southside, 7th Floor, 105

Victoria Street, London SW1E 6QT, UK 
An example of regulatory and HTA misalignment around UMNs: Polivy for diffuse large B-cell lymphoma in France

The absence of a shared understanding of UMNs can lead to inconsistent decisions or priorities between stakeholders, leading in turn to delays or barriers to development. We suggest that such a misalignment explains at least some of the experience of Polivy (polatuzumab vedotin) under France's Temporary Use Authorisation (ATU) scheme.

The primary objective of the ATU is accelerated patient access to promising medicines not yet covered by a marketing authorisation in France, particularly in areas of recognised UMN. To achieve faster access, promising medicines are made available through the ATU before they are granted European Medicines Agency marketing authorisation and before an HTA reimbursement decision is made. There is an evidence generation element in the ATU, but in contrast to "coverage with evidence generation" schemes such as the UK's Cancer Drugs Fund, this is not a primary objective of the ATU and the data generated through the scheme are not typically a critical element of the HTA

Polivy - a first-in-class treatment for diffuse large B-cell lymphoma, a rare but fatal condition - was accepted into the ATU on the basis of a phase Ib/II study [7, 8] and authorised for use by the European Medicines Agency [9]. However, France's HTA agency, the Haute Autorité de Santé (HAS), subsequently rejected Polivy for reimbursement on the basis of the same package of evidence submitted to the ATU [10]. The HAS judged that Polivy "did not provide a sufficient medical benefit or public health benefit to justify a place in the treatment of adult patients ..." [10]. It is notable that HAS's judgement did not reference value for money and appears to be based entirely on perceived health benefits.

There is considerable overlap in the criteria for ATU eligibility and HAS reimbursement: both emphasise relative efficacy/effectiveness and safety, disease severity and rarity, and the availability of alternative therapies $[11,12]$. However, ATU deemed Polivy to be promising enough in addressing a recognised UMN to grant accelerated access, whilst HAS saw essentially the same evidence as insufficient to justify a place in treatment. This outcome suggests an important misalignment in understanding between two closely related agencies that should, in principle, be working in concert. Similar misalignment between regulators and assessors has been noted elsewhere, [13] and represents a key barrier to effectively addressing UMNs.

\section{Towards a Shared Understanding of UMN}

Misalignment between stakeholders around UMN, as well as perceptions of opportunism in its application, [14] have led to calls for 'genuine' UMNs to be more effectively distinguished from less pressing health needs [6]. However, given the diversity of stakeholders and contexts represented along the medicines development pathway, we suggest that any process of arriving at a shared understanding of 'genuine UMNs' must begin with principles that can be understood without reference to context. Central to this approach is recognising that stakeholders may reasonably disagree over the relevance of specific elements in setting priorities, but can nevertheless identify a set of rationale, based on different visions of 'fairness', upon which a set of principles for priority setting might be agreed $[15,16]$.

On this basis, we suggest that stakeholders must 'cocreate' a conceptual framework for understanding UMN, based on a pragmatic combination of outcomes-oriented and process-oriented visions of justice. Outcomes-oriented, or substantive, visions of justice focus on the fairness of the outcome without consideration of the process, whereas process-oriented visions of justice emphasise fairness in how an outcome is reached without prescribing the outcome itself $[17,18]$. We believe that 'procedural justice', in the form of a fair and inclusive deliberative process, is essential for the legitimacy and broad acceptance of any resulting understanding of UMN, whilst consideration of 'substantive' theories of justice provides a useful structure for discussion. Given the complexity of UMN as a concept, a purely procedural approach with no explicit vision of a fair outcome may struggle to reach consensus, whilst an emphasis on outcomes at the expense of a fair and inclusive process will struggle to demonstrate legitimacy.

We suggest that the substantive principles included in this process are likely to include concerns for need (i.e. resources should be prioritised in proportion to need, often in terms of severity); inequality (i.e. resources should be prioritised so as to reduce inequalities); and well-being maximisation (i.e. resources should be prioritised to maximise aggregate well-being) [19]. As illustrated in Fig. 1, the various elements of UMN described by Vreman et al. [4], including aspects of availability, disease burden and patient characteristics, can each be seen to embody one or more of these principles. For example, criteria related to disease severity can be seen to reflect need principles, concerns for disease burden (especially prevalence) can be seen to reflect maximising principles and concerns for the availability of alternative treatments arguably reflect equality principles as well as need principles. We acknowledge, though, that different readers may see different principles reflected in different elements of UMN.

This is not to imply that these are the only principles that are relevant to understanding UMN, but we do suggest that these principles are a useful starting point given their prominence in many discussions of distributive justice in health $[17,19,20]$. We intentionally avoid an overly prescriptive or structured approach as we believe any process of re-conceptualising UMN must be stakeholder led to achieve consensus over identified principles. This framework is intended to help start that process of deliberation and consensus.

We see the primary advantage of a principles-based framework as providing a common vocabulary for discussing UMN at the level of objectives rather than specific criteria. For example, rather than focusing on how many treatment alternatives should be available before an UMN around availability is no longer considered 'unmet', discussions 


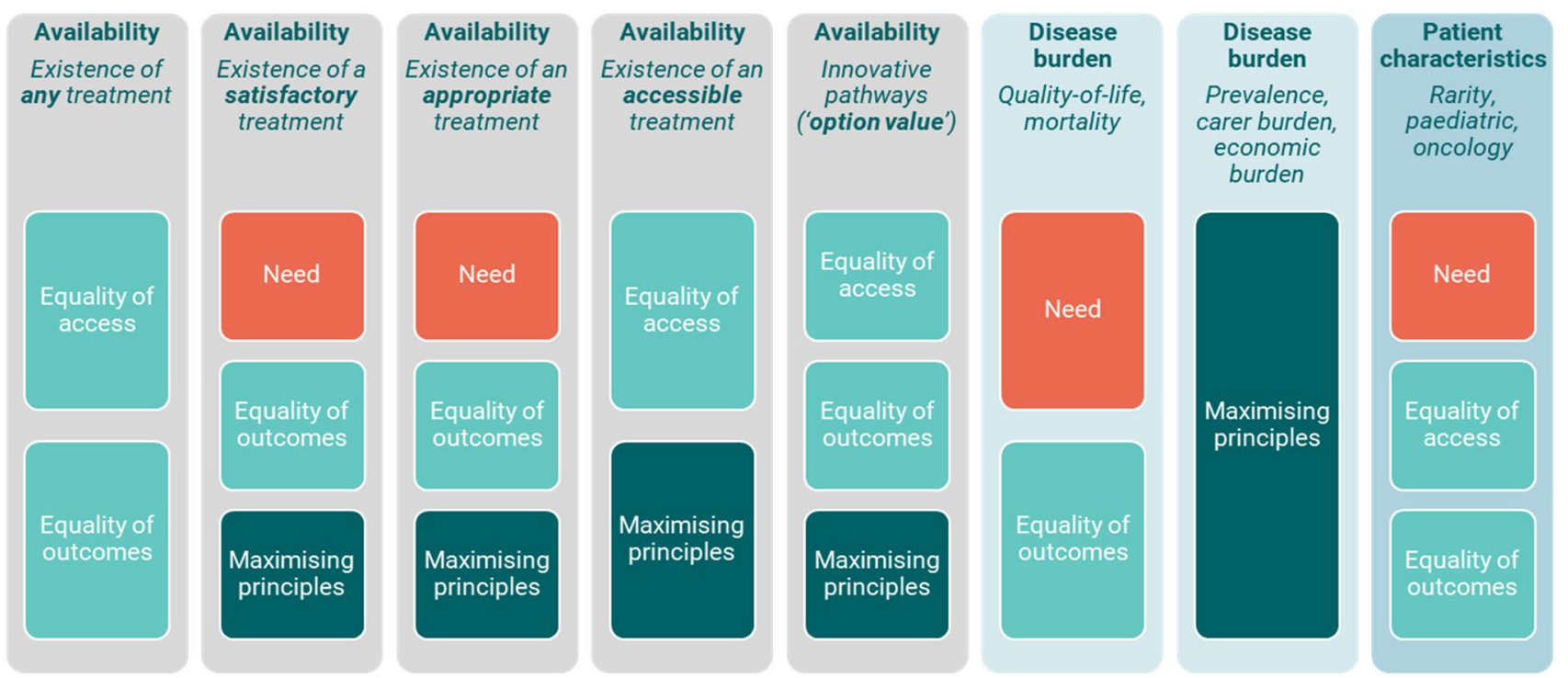

Fig. 1 Illustration of key principles within elements of unmet medical need

could focus on agreeing how equality in access or health outcomes might be understood and recognised. An agreement on this principle would then inform context-specific criteria to identify which conditions fail to meet this objective and may therefore represent an UMN.

Furthermore, given maximising principles are already the explicit basis of many existing value frameworks [21, 22], framing objectives for UMN around compatible distributive principles such as need and equality would, in theory, allow these concerns to be incorporated into these frameworks and considered on an equal ethical basis to maximising objectives.

\section{Challenges in the Application of a New Framework}

We do not mean to underestimate the difficulty of reaching consensus on a set of shared objectives around UMN. Simply encouraging stakeholders to explicitly acknowledge and prioritise different objectives would represent progress, though, as it would require them to justify their objectives and to acknowledge the legitimacy of the objectives of others.

A key challenge, even at the conceptual level described here, is that these principles represent often conflicting concerns, such as the incompatible objective of simultaneously equalising and maximising outcomes. Hence, trade-offs will need to be made between objectives, and each stakeholder may assign a different importance to each objective. Health technology assessment bodies, for example, may prioritise maximising objectives over concerns for need or equality, whilst research funders may be more likely to focus on need principles over aggregate benefits. However, discussing differing priorities and objectives at the level of distributive principles rather than quantitative criteria allows stakeholders to consider trade-offs between objectives in a more constructive manner than is possible under the often binary and disconnected criteria by which we currently understand UMNs. Mutual consideration and recognition would represent progress from the current situation of misaligned and often suspicious understanding of the objectives of others.

Agreeing on a principles-based framework will not in itself provide an operational definition of UMN. However, it is an important initial step towards reconceptualising UMN to improve alignment between stakeholders and provide a more reliable and consistent signal to innovators. Future steps in developing an operational definition of UMN may involve an empirical study of population values to derive the ethical principles for allocating healthcare [23]. This would provide insights into public attitudes and preferences, such as society's views on which tradeoffs between objectives (e.g. maximising vs equalising outcomes) are considered acceptable, and which are not, and translating these principles into consistent but contextspecific criteria for identifying UMNs and incentivising future innovation.

\section{Declarations}

Author Contributions All authors contributed to the preparation and review of the final manuscript. 
Funding This work was funded by the European Federation of Pharmaceutical Industries and Associations.

Conflict of Interest Kyann Zhang, Gayathri Kumar and Chris Skedgel have no conflicts of interest that are directly relevant to the content of this article.

Open Access This article is licensed under a Creative Commons Attribution-NonCommercial 4.0 International License, which permits any non-commercial use, sharing, adaptation, distribution and reproduction in any medium or format, as long as you give appropriate credit to the original author(s) and the source, provide a link to the Creative Commons licence, and indicate if changes were made. The images or other third party material in this article are included in the article's Creative Commons licence, unless indicated otherwise in a credit line to the material. If material is not included in the article's Creative Commons licence and your intended use is not permitted by statutory regulation or exceeds the permitted use, you will need to obtain permission directly from the copyright holder. To view a copy of this licence, visit http://creativecommons.org/licenses/by-nc/4.0/.

\section{References}

1. European Commission. Pharmaceutical strategy for Europe. 2020. https://ec.europa.eu/health/sites/health/files/human-use/docs/ pharma-strategy_report_en.pdf. Accessed 22 Apr 2021.

2. Bartels HG, World Health Organization, World Intellectual Property Organization, et al., editors. Promoting access to medical technologies and innovation: intersections between public health, intellectual property, and trade. Geneva: World Health Organization, World Intellectual Property Organization, World Trade Organization; 2013. https://www.who.int/phi/PAMTI_WHOWIPO-WTO.pdf. Accessed 20 Oct 2020.

3. European Commission. Pharmaceutical strategy for Europe Workshop summary, 14-15 July 2020. 2020. https://ec.europa.eu/health/ sites/health/files/human-use/docs/stakeholders_sum_workshop_ en.pdf. Accessed 14 Oct 2020.

4. Vreman RA, Heikkinen I, Schuurman A, et al. Unmet medical need: an introduction to definitions and stakeholder perceptions. Value Health. 2019;22:1275-82. https://doi.org/10.1016/j.jval. 2019.07.007.

5. Saesen R, Lejeune S, Quaglio G, et al. Views of European drug development stakeholders on treatment optimization and its potential for use in decision-making. Front Pharmacol. 2020;11:43. https://doi.org/10.3389/fphar.2020.00043.

6. European Commission. Pharmaceutical strategy: timely patient access to affordable medicines. 2020. https://ec.europa.eu/info/ law/better-regulation/have-your-say/initiatives/12421-Pharmaceut ical-Strategy-Timely-patient-access-to-affordable-medicines. Accessed 14 Oct 2020.

7. Ministère des Solidarités et de la Santé. Autorisations temporaires d'utilisation (ATU). 2020. https://solidarites-sante.gouv.fr/soinset-maladies/medicaments/professionnels-de-sante/autorisationde-mise-sur-le-marche/article/autorisations-temporaires-d-utili sation-atu. Accessed 29 Sep 2020.

8. Roche. European Commission approves Roche's Polivy for people with previously treated aggressive lymphoma. https://www.roche. com/media/releases/med-cor-2020-01-21.htm. Accessed 29 Sep 2020.

9. European Medicines Agency. Polivy. 2019. https://www.ema. europa.eu/en/medicines/human/EPAR/polivy. Accessed 1 Oct 2020.

10. Haute Autorité de Santé. POLIVY. https://www.has-sante.fr/ jcms/p_3196691/fr/polivy. Accessed 29 Sep 2020.

11. Agence Nationale de Sécurité du Médicament et des Produits de Santé. Notice to applicants for marketing for temporary authorisation for use (ATU). 2015. https://www.ansm.sante.fr/content/ download/79919/1011615/version/1/file/Notice-aaplicants-marke ting_ATU.pdf\&usg=AOvVaw2MO7aPtAbe8Cd-bMTEghY1. Accessed 22 Apr 2021.

12. Haute Autorité de Santé. Transparency Committee doctrine: principles of medicinal products assessment and appraisal for reimbursement purposes. 2018. https://www.has-sante.fr/upload/docs/ application/pdf/2019-07/doctrine_de_la_commission_de_la_trans parence_-_version_anglaise.pdf. Accessed 22 Apr 2021.

13. Wang T, McAuslane N, Liberti L, et al. Building synergy between regulatory and HTA agencies beyond processes and procedures: can we effectively align the evidentiary requirements? A survey of stakeholder perceptions. Value Health. 2018;21:707-14. https:// doi.org/10.1016/j.jval.2017.11.003.

14. BEUC. BEUC position on access to medicines. The European Consumer Organisation. 2015. https://www.beuc.eu/publicatio ns/beuc-x-2015-104_access_to_medicines.pdf. Accessed 20 Oct 2020.

15. Daniels N, Sabin J. Limits to health care: fair procedures, democratic deliberation, and the legitimacy problem for insurers. Philos Public Aff. 1997;26:303-50. https://doi.org/10.1111/j.1088-4963. 1997.tb00082.x.

16. Hasman A, Holm S. Accountability for reasonableness: opening the black box of process. Health Care Anal. 2005;13:261-73. https://doi.org/10.1007/s10728-005-8124-2.

17. Williams A, Cookson R. Equity in health. In: Culyer AJ, Newhouse JP, editors. Handbook of health economics. Amsterdam: Elsevier; 2000. p. 1863-910.

18. Rawls J, Kelly E. Justice as fairness: a restatement. Cambridge: Harvard University Press; 2001.

19. Cookson R, Dolan P. Principles of justice in health care rationing. J Med Ethics. 2000;26:323-9. https://doi.org/10.1136/jme.26.5. 323.

20. Konow $\mathrm{J}$. Which is the fairest one of all? A positive analysis of justice theories. J Econ Lit. 2003;41:1188-239. https://doi.org/10. 1257/002205103771800013.

21. Seixas BV, Dionne F, Conte T, et al. Assessing value in health care: using an interpretive classification system to understand existing practices based on a systematic review. BMC Health Serv Res. 2019;19:560. https://doi.org/10.1186/s12913-019-4405-6.

22. Expert Panel on Effective Ways of Investing in Health. Defining value in "value-based healthcare." European Commission. 2019. https://ec.europa.eu/health/sites/health/files/expert_panel/docs/ 024_defining-value-vbhc_en.pdf. Accessed 26 Mar 2021.

23. Richardson J, McKie J. Empiricism, ethics and orthodox economic theory: what is the appropriate basis for decision-making in the health sector? Soc Sci Med. 2005;60:265-75. https://doi. org/10.1016/j.socscimed.2004.04.034. 